\title{
A Avaliação na Educação Física Escolar: Uma Comparação entre as Escolas Tradicional e Ciclada
}

\author{
Josiane Diniz*
}

Sílvia Cristina Franco Amaral ${ }^{* *}$

\begin{abstract}
Resumo: No presente trabalho, realizou-se uma análise comparativa entre as escolas tradicional e ciclada, pensando em como se daria a avaliação na Educação Física a partir destas duas perspectivas. Para desenvolver o estudo foi essencial analisar as estruturas escolares: currículo, base teórica, metodologia de ensino, projeto político-pedagógico; bem como, as funções sociais exercidas por estas escolas e as relações construídas por elas no cotidiano escolar. Como resultado deste estudo verificou-se que a avaliação em Educação Física, realizada por essas escolas, utiliza instrumentos avaliativos semelhantes, tais como: a presença em aula, a autoavaliação e o desempenho dos alunos, além de aulas teóricas e testes escritos. Entretanto, a avaliação realizada pela escola tradicional é orientada para a seleção e classificação dos discentes, diferentemente da escola ciclada, cuja avaliação é orientada para o desenvolvimento da aprendizagem e para a formação de indivíduos socialmente ativos e autônomos, capazes de refletir sobre a própria prática e sobre a realidade social a qual pertencem.
\end{abstract}

Palavras-chave: Educação Física. Avaliação. Currículo. Ensino fundamental e médio.

\section{INTRODUÇÃo}

A avaliação é um elemento complexo e possui características social, histórica e pessoal, que lhe conferem poder de influenciar a vida das pessoas e as situações em que vivem. Ela reflete a forma como o professor pensa sua concepção de mundo, sua ética, sua

\footnotetext{
* Licenciada em Educação Física - Faculdade de Educação Física - Unicamp. Departamento de Educação Motora - Faculdade de Educação Física-Unicamp. Campinas, SP, Brasil. E-mail: jo2002diniz@hotmail.com

** Doutora em Educação Física - Departamento de Educação Motora - Faculdade de Educação Física-Unicamp. Departamento de Educação Motora - Faculdade de Educação Física - Unicamp. E-mail: scfa@fef.unicamp.br
} 
forma de ver o aluno e seus conhecimentos sobre o processo ensinoaprendizagem, sobre a escola e sobre sua função.

No cenário escolar destacam-se diferentes modelos ou concepções de ensino e de avaliação, sendo que, na maioria está presente a avaliação formal realizada pelo professor e constituída de procedimentos e atividades avaliativas aplicáveis aos alunos. Essa forma de avaliação é a mais utilizada dentro da escola tradicional, sendo considerada artificial por não ter uma relação com a realidade vivida pelos alunos, que apenas estudam para adquirir uma nota. Freitas (2003b, p. 28) afirma que neste tipo de concepção de ensino

[...] o aluno é cada vez mais conformado a ver a aprendizagem como algo que só tem valor a partir da nota (ou aprovação social) que lhe é externa e a troca pela nota assume o lugar de importância do próprio conhecimento como construção pessoal e poder de interferência no mundo.

A avaliação formal também está presente na escola ciclada, porém busca-se associar a ela ações complementares (reforço, recuperação paralela) que auxiliem no processo de aprendizagem do aluno, enfatizando o conhecimento real adquirido e sua relação com a vida do discente.

Diante de importantes discussões e informações existentes a respeito da avaliação escolar, o objetivo deste trabalho é realizar uma comparação entre a avaliação na escola tradicional e na escola ciclada, dando ênfase às semelhanças e diferenças nas formas como essas escolas se organizam, pensam e programam a avaliação e como poderia/deveria ser esta na Educação Física.

Ao delimitarmos este estudo, optamos por efetuar uma pesquisa de revisão e análise bibliográfica utilizando revistas, livros e artigos, no período de 1986 a 2005. A delimitação deste período foi determinada por ser este o de maior incidência de discussões e publicações sobre a avaliação escolar, a escola ciclada e seus resultados na realidade brasileira.

Movimento, Porto Alegre, v. 15, n. 01, p. 241-258, janeiro/março de 2009. 


\section{A ESCOLA TRADICIONAL}

A escola tradicional pública nasceu no século XIX, após a revolução industrial, com a intenção de preparar a população para as novas perspectivas de trabalho que estavam surgindo.

Partindo da lógica capitalista, percebe-se que o homem é visto, pela escola tradicional, como sendo parte de um mundo, que lhe é externo e do qual ele deve assimilar as informações (domínio do mundo), no decorrer de sua trajetória escolar e de sua vida.

Para a escola tradicional, a compreensão e domínio do mundo, significam a assimilação dos saberes que interessam à sociedade capitalista, e têm a função de servir como instrumentos, para que os indivíduos que os possuam, utilizem-os na instrução de outros e/ou para tornar-se um profissional eficiente.

Deve-se entender que, para a lógica capitalista que impulsionou o surgimento de uma escola que "trabalhe" sob seus princípios, imprimindo a ela a função utilitarista de preparação dos indivíduos para o mercado de trabalho, o eficiente é o indivíduo capacitado a realizar tarefas com o máximo aproveitamento dos materiais e do tempo, ou seja, o indivíduo mais produtivo.

A escola tradicional, por estar inserida numa sociedade que busca frenéticamente o lucro e a produtividade. Impregnada por tais princípios, tornou-se um instrumento eficaz de seleção e de manutenção das hierarquias sociais. Para compreender como esses processos operam-se, é necessário ter-se claro como a escola é estruturada e como ela pensa e programa os saberes escolares e o processo ensino-aprendizagem.

A conformação que a escola apresenta de maneira alguma pode ser encarada como sendo despropositada. A organização e pré-determinação dos conteúdos e modelos a serem transmitidos aos alunos e assimilados por eles são realizadas com base na ordem capitalista e na função estabelecida por esta à escola.

Ao proporcionar um ensino padronizado aos diferentes indivíduos, que compõe uma mesma sala de aula, advindos de diversas classes

Movimento, Porto Alegre, v. 15, n. 01, p. 241-258, janeiro/março de 2009. 
sociais, com histórias de vidas distintas, sem considerar a individualidade e singularidade cultural de cada um, e ao selecionar conteúdos externos aos alunos e que vão ao encontro das necessidades do mercado, tendo por objetivos e conseqüências a seleção e exclusão social e a reprodução das hierarquias, a escola não se constitui como espaço de correção das desigualdades sociais (equidade social) e não pode ser considerada neutra e ingênua.

\section{A AVALIAÇÃo NA ESCOLA TRADICIONAL}

A avaliação surge no contexto da escola tradicional, sendo instituída dentro da sala de aula, por dois motivos: necessidade de mensurar, quantificar a assimilação dos conteúdos, e necessidade de motivar a aprendizagem. O primeiro motivo ocasionou a elaboração de testes/ provas e exercícios orais e escritos, bem como a construção e aplicação de seminários, que possibilitassem ao aluno demonstrar o seu conhecimento sobre determinado assunto, e ao docente conhecê-los. O segundo motivo extremamente relevante para o tema ocorreu devido à separação/distanciamento da vida escolar da prática e vida social do aluno, que não reconhecendo os conteúdos como informações relevantes para sua realidade acabou perdendo os motivadores internos e necessitando de motivadores externos (artificiais) para a assimilação dos mesmos.

\footnotetext{
A necessidade de introduzir mecanismos artificiais de avaliação (provas, testes, etc.) foi motivada pelo fato de a vida ter ficado do lado de fora da escola. Com isso, ficaram lá também os 'motivadores naturais’ para a aprendizagem, obrigando a escola a lançar mão de 'motivadores artificiais' - foi desenvolvido um sistema de avaliação com notas como forma de estimular a aprendizagem e de controlar o comportamento de contingentes cada vez maiores de crianças que acudiam à escola e tinham de ficar dentro delas, imobilizadas, ouvindo o professor. O isolamento e o artificialismo da escola levaram a uma avaliação igualmente artificial (FREITAS, 2003b, p. 27-28).

$[\ldots]$

Isso colocou como centro da aprendizagem a aprovação do professor, e não a capacidade de intervir
}

Movimento, Porto Alegre, v. 15, n. 01, p. 241-258, janeiro/março de 2009. 
na prática social. Aprender para 'mostrar conhecimento ao professor' tomou o lugar do 'aprender para intervir na realidade'. Essa é a raiz do processo avaliativo artificializado da escola [...] (FREITAS, 2003b, p. 40).

Imbuída destas características funcionais (instrumento quantificador de aprendizagem e motivador externo), a avaliação foi adquirindo papéis de destaque dentro da escola tradicional, tornando-se um elemento fundamental para a seleção e exclusão social, e, por isso, um momento de grande expectativa e preocupação para pais, alunos e professores, visto que seus resultados finais influenciam de forma definitiva a vida pessoal e profissional do discente.

A avaliação atua como instrumento de seleção e exclusão social à medida que é estruturada e pensada a partir dos conteúdos, externos aos alunos, e que seus resultados são traduzidos em números que determinam à aprovação ou reprovação do indivíduo. Não há uma preocupação em verificar a evolução do discente, durante o processo ensino-aprendizagem, e sim de verificar se houve a assimilação de determinado conteúdo.

Conforme Freitas, a avaliação possui, minimamente, três componentes:

O primeiro deles é o aspecto 'instrucional' - o lado mais conhecido da avaliação -, pelo qual se avalia o domínio de habilidades e conteúdos em provas, chamadas, trabalhos e etc. [...] O segundo componente, constituído pela avaliação do 'comportamento' do aluno em sala, é um poderoso instrumento de controle em ambiente escolar, já que permite ao professor exigir do aluno obediência às regras. O poder dessa exigência está ligado, ao fato de o professor ter a possibilidade de aprovar ou reprovar a partir do elemento anterior, ou seja, a partir da avaliação da instrução. [...] Finalmente, existe o terceiro aspecto: a avaliação de 'valores e atitudes', que ocorre cotidianamente em sala de aula e que consiste em dispor o aluno a reprimendas verbais e físicas, comentários críticos e até humilhação perante a classe, criticando seus valores e suas atitudes (FREITAS, 2003b, p. 41-42).

Movimento, Porto Alegre, v. 15, n. 01, p. 241-258, janeiro/março de 2009. 
Sobre a relação destes componentes da avaliação com as funções exercidas pela escola, Freitas (2003b, p. 42-43) enfatiza que

[...] é no campo da avaliação de valores e atitudes, bem como no da avaliação do comportamento do aluno, que se instala preferencialmente a lógica da submissão. A utilização da avaliação instrucional em articulação com estas duas outras dimensões cria o campo necessário para que se exercitem relações sociais de dominação e submissão ao professor e à ordem.

Um aspecto interessante que Freitas salienta é o de que a avaliação escolar ocorre em duas perspectivas: na formal e na informal. Na perspectiva formal incluem-se as metodologias e elementos concretos da avaliação, tais como, as provas e exercícios; na perspectiva informal estão os "juízos de valor", que surgem das relações diárias entre professor e alunos. Esses juízos, em geral, interferem diretamente na forma como os indivíduos dessas relações se enxergam, e consequentemente, nas posturas e decisões tomadas pelos mesmos. Caso o professor não tenha sido preparado para solucionar/ bloquear os 'juízos de valor' que tem de seus alunos, ele pode sofrer interferências destes na elaboração de suas aulas, na sua motivação para o trabalho e na avaliação dos alunos.

Na escola tradicional, a ênfase é dada na avaliação formal. A maioria dos professores ou desconhecem a face informal da avaliação ou não creditam a ela tanta importância. Diante de falhas e/ou do fracasso escolar critica-se o professor, o aluno e não a forma como ocorre o processo ensino-aprendizagem, a forma como a escola é organizada e até mesmo o sistema que rege a sociedade.

\section{A escola CicLada}

As décadas de 1980 e 1990 foram marcadas por inúmeras discussões sobre a escola, os elevados índices de repetência e evasão, o currículo, a avaliação, etc. Com o aumento da repercussão dessas discussões e do descontentamento dos indivíduos ligados aos processos educacionais - educadores, pais, pesquisadores - surgiram novas formas de ensino, dentre elas, a escola organizada em ciclos de

Movimento, Porto Alegre, v. 15, n. 01, p. 241-258, janeiro/março de 2009. 
formação. Essa forma de ensino fortaleceu-se com a aprovação da Lei de Diretrizes e Bases (LDB) nº. 9.394/96, que previu a implantação de ciclos de formação na educação básica. Contudo, essa lei não especificou como esses ciclos deveriam ser organizados, deixando brechas para que surgissem diversas formas de aplicação e conceituação dos mesmos.

Freitas (2003 a) nos informa que houve, no Brasil, várias iniciativas de implantação dos ciclos em diversos estados:

\begin{abstract}
[...] as iniciativas das redes municipais de São Paulo, Belo Horizonte e Porto Alegre, que se pautaram pelo compromisso de construção de uma nova organização escolar, comprometida com a democratização do ensino. Apesar de suas especificidades, alguns traços foram comuns nessas iniciativas, dentre elas: estruturação curricular sob eixos temáticos e não exclusivamente disciplinares; valorização das experiências e conhecimentos dos alunos; consideração das diferenças entre os educandos na interação com o trabalho escolar; ênfase no trabalho coletivo, tanto docente quanto discente; avaliação formativa, sem fins classificatórios; organização por agrupamento de alunos, com base em objetivos de aprendizagem e grupos etários (FREITAS 2003 a, p. 88).
\end{abstract}

Para fins de organização e clareza do presente trabalho, utilizaremos o conceito de que a escola organizada em ciclos seja aquela que apresente seus tempos e espaços divididos em ciclos de formação, "[...] que se baseiam em experiências socialmente significativas para a idade do aluno" (FREITAS, 2003b, p. 09), podendo ser nomeada de escola cidadã, escola plural e/ou escola ciclada.

A escola ciclada tem por base idéias construtivistas e a partir delas o conceito de que a aprendizagem e conhecimento ocorrem por processo gradual, partindo de elementos simples e significativos ao sujeito e que dependem da estrutura interna deste, sendo, por isso mesmo, um processo individual, ou seja, os sujeitos necessitam de tempos diferenciados para completar cada fase do processo. "Daí a justificativa, da não seriação na educação fundamental, mas ciclos, respeitando o estágio de desenvolvimento em que a criança se encontra [...]" (ALVARENGA, 1999, p. 161).

Movimento, Porto Alegre, v. 15, n. 01, p. 241-258, janeiro/março de 2009. 
A escola ciclada organizou seus tempos escolares em ciclos de formação, sendo que, em geral, o primeiro ciclo compreende os alunos de 6 a 9 anos de idade, o segundo ciclo, aluno de 9 a 12 anos e o terceiro, de 12 a 14 anos de idade. Segundo Dalben (2000, p. 53) "[...] o ciclo, para a Escola Plural, é um tempo contínuo que se identifica com o tempo de formação do próprio desenvolvimento humano: infância, puberdade e adolescência."

Essa forma de organização escolar visa romper com a seleção e exclusão realizadas dentro da escola tradicional, pois acredita que através da criação de tempos diferenciados de aprendizagem, maneiras flexíveis de construção de conhecimento, aproximação da escola e de seus conteúdos a realidade do aluno, seja possível realizar a inclusão real deste à escola e à sociedade.

A escola ciclada procura proporcionar um ensino de qualidade, que atinja os objetivos de: construir um ensino democrático, ou seja, a todos os indivíduos igualmente e sem restrições e de realizar a formação de indivíduos e cidadãos críticos, autônomos, capazes de refletir e interferir na sociedade e que compreendam e respeitem seus deveres e direitos.

Além da organização de ciclos de formação baseados nas fases de desenvolvimento humano e nos objetivos de aprendizagem, outras estruturas inovadoras nessa escola são: a valorização do conhecimento prévio à escola, as diferenças de tempos de aprendizagem entre os discentes e a organização dos coletivos de docentes que compartilham a responsabilidade pela aprendizagem em cada ciclo.

Todas essas estruturas corroboram para que ocorra uma aprendizagem real a partir do momento que elas contribuem para a significação e a aproximação dos conteúdos à realidade dos discentes e para a horizontalização do poder, ao retirar das mãos dos professores, o total domínio sobre o conhecimento e enfatizar e proporcionar vivências de ações e trabalhos coletivos.

Os defensores da escola ciclada dizem que esta se realiza através de uma escola democrática que proporcione aos discentes, vivências concretas da vida e da situação social, pode-se alcançar os objetivos de construção de uma educação de qualidade e a formação de indivíduos

Movimento, Porto Alegre, v. 15, n. 01, p. 241-258, janeiro/março de 2009. 
capazes de produzir novos conhecimentos e que busquem melhores condições de vida para toda a sociedade.

\section{A AVALIAÇÃO NA ESCOLA CICLADA}

Como uma das importantes estruturas da escola ciclada, a avaliação, nessa escola rompe com as tradições da escola seriada (tradicional) e propõe-se a contribuir com o processo de aprendizagem e o desenvolvimento do aluno.

Buscando este objetivo, a escola ciclada programa uma avaliação que procura conhecer, através das análises dos erros, a dimensão e profundidade do conhecimento apresentado pelo discente, para assim conduzi-lo a novos caminhos para a aprendizagem dos conteúdos e para estimulá-lo a evoluir e produzir conhecimento. Nesse sentido, os resultados das avaliações (que se constituem a própria avaliação na escola tradicional) são partes do processo de construção do saber e oportunidade de verificação e reflexão da prática escolar e das demais práticas do discente.

Para compreendermos ainda mais a avaliação na escola ciclada tomemos o exemplo trazido por Freitas (1999, p. 52), quando analisa o caso da Escola Cidadã de Porto Alegre. "Na escola cidadã ocorrem três modalidades de avaliação: a avaliação formativa [...], somativa e especializada". Explica o autor que a primeira destina-se a informar a situação em que se encontra o educando em relação ao progresso de sua aprendizagem em um trimestre. A segunda, é aquela que disponibiliza um quadro geral do educando ao final de cada ano letivo ou ciclo de aprendizagem. A terceira e última, é realizada pelo "Serviço de Orientação Pedagógica, com o apoio do Laboratório de Aprendizagem e da Sala de Integração e Recursos (SIR), além de outros serviços especializados" (FERREIRA, 2003, p. 94) que visa a avaliação daqueles alunos que por ventura necessitam de apoio educativo individualizado.

No contexto das perspectivas formal e informal da avaliação, observa-se que ambas se mantêm dentro da escola ciclada, porém apresentam novas formas de conduta e funções. Essas novas características são consequiências do direcionamento e utilização dos resultados da

Movimento, Porto Alegre, v. 15, n. 01, p. 241-258, janeiro/março de 2009. 
avaliação formal e da mudança nas relações entre professores e alunos (horizontalização do poder sobre o conhecimento) que influenciam diretamente a avaliação informal. Com a relativização do poder - instituído ao professor pela escola tradicional com base ao seu maior domínio do conhecimento e a possibilidade da reprovação do discente -, a escola ciclada proporciona um relacionamento natural, entre professores e alunos, de troca de informações e assim contribui para a aprendizagem e para a produção de conhecimento.

\section{A EDUCAÇÃo FísicA E A AVALIAÇÃo SOB OS MOLDES dA ESCOLA TRADICIONAL}

Como elemento da escola tradicional, a Educação Física também surge com caráter assistencialista, sendo suas funções: preparar fisicamente os "futuros trabalhadores" das indústrias capitalistas, desenvolver e inculcar no povo as características fundamentais de sobrevivência que este sistema social exigia e que o crescimento das aglomerações urbanas determinava, tais como: organização das cidades, saneamento básico e higienização do corpo.

Assim, desde o seu surgimento, a Educação Física foi desenvolvida de acordo com as necessidades de cada período histórico e seus aspectos políticos, sociais e econômicos interessantes às classes dominantes.

Das diversas tendências que surgiram, o paradigma da aptidão física e a esportivização da Educação Física, foram considerados e utilizados como conteúdos inerentes à EF nas escolas tradicionais até nos anos de 1980, e ainda, nos dias atuais, são conteúdos frequentes nas aulas. Na década de 1980, surgiram discursos e críticas sobre a EF e o paradigma da aptidão física, que fomentaram a elaboração de novas e diversas teorias que objetivavam orientar a EF na escola e na área acadêmica. De acordo com Betti (1991, p. 116):

O período caracterizou-se por um questionamento da situação estabelecida nos períodos anteriores, pela percepção de uma situação de crise no setor educacional, e por uma radical mudança de discursos

Movimento, Porto Alegre, v. 15, n. 01, p. 241-258, janeiro/março de 2009. 
e de referenciais conceituais na Educação Física, caracterizando uma verdadeira crise de identidade.

A diversidade de teorias que surgiram, proporcionaram o aparecimento de uma pluralidade de práticas e metodologias, encontradas atualmente nas escolas e universidades.

Contudo, apesar dessa pluralidade, na EF atual, realizada pela escola tradicional, é possível observar o predomínio de metodologias de caráter biologicistas e tecnicistas, que valorizam e enfatizam, respectivamente, os fatores anatômicos, fisiológicos, biomecânicos e as técnicas e táticas desportivas. Para comprovar tal situação, basta observar que nas aulas de $\mathrm{EF}$, cujos conteúdos mais frequentes são os esportes coletivos, a preocupação dos professores é o aprendizado das regras, o desempenho técnico e tático dos alunos, nos esportes selecionados, o condicionamento físico e a verificação/descoberta e seleção de novos atletas.

Dentro desse contexto pode-se observar que o esporte, como é tratado e desenvolvido pela escola tradicional (descontextualizado da realidade histórica e social que representa, e sendo enfatizado nos seus aspectos técnicos, táticos e no competitivo), configura-se como uma forma de alienação social. Isto ocorre porque o trato desse conteúdo acontece de forma acrítica e restrita. A EF escolar atrelada aos esportes deixa de desenvolver os demais conteúdos da cultura corporal, relevantes para a formação dos discentes.

Essa forma de organização da EF que a transforma em uma disciplina de características acrítica, a-histórica, e que conduz ao fazer pelo fazer, tem como base a postura e a função assumida, por essa disciplina, de não responsabilidade com a formação intelectual e social dos discentes e o comprometimento com somente o desenvolvimento das habilidades motoras.

Vários são os motivos da relativa importância que a EF tem na realidade escolar. Ao menos três deles se apresentam de forma mais contundente. Primeiro, a EF ao lidar com o corpo, parece ter construído para si, na escola tradicional, uma visão dicotômica de ser humano. Isto é perpetuado não só pelo senso comum, mas também

Movimento, Porto Alegre, v. 15, n. 01, p. 241-258, janeiro/março de 2009. 
pela própria área na qual a EF, como debate acadêmico, está inserida, ou seja, as Ciências da Saúde. Um segundo motivo, imbricado com o primeiro, é que a escola tradicional valoriza os conhecimentos intelectuais e desvaloriza os conhecimentos, ditos "corpóreos". Ora, esquece-se a escola tradicional que

O corpo é a síntese da cultura, porque expressa elementos específicos da sociedade da qual faz parte. O homem, por meio do corpo, vai assimilando e se apropriando de valores, normas e costumes sociais, num processo de inCORPOração (a palavra é significativa). Mais do que um aprendizado intelectual, o indivíduo adquire um conteúdo cultural, que se instala no seu corpo, no conjunto de suas expressões (DAOLIO, 2003, p. 67).

Um terceiro e grave motivo da desvalorização da EF na escola tradicional é o espaço restrito e restritivo que a EF ocupa, seja ao não tratar de assuntos sóciopolíticos nos seus conteúdos ou, a, muitas vezes, não ser chamada a tomar parte das reuniões pedagógicas da escola, seja por desenvolver atividades ligadas exclusivamente a habilidades motoras ou por executar tarefas auxiliares às demais disciplinas, sem qualquer trabalho coletivo com outros docentes.

A relativa importância dada à Educação Física, pela escola tradicional e por profissionais, que não atribuem a ela, relevância para a formação dos discentes, reflete-se na avaliação que esta realiza. Uma vez que, essas posturas não são ingênuas e atuam na direção de contribuir para que as funções desta escola, de classificação e seleção dos indivíduos para o mercado de trabalho e de perpetuação das hierarquias sociais sejam alcançadas, a escolha e a aplicação da avaliação em EF, nesta escola, serão orientadas para fazer o mesmo. O que explica a constante realização de avaliações que não apresentam qualquer planejamento relacionado com objetivos complexos de desenvolvimento dos conteúdos e da formação dos discentes. Na grande maioria das vezes, as avaliações realizadas objetivam predominantemente, segundo Soares et al. (1992, p. 98), "[...] (a) atender exigências burocráticas expressas em normas da escola; b) atender a legislação vigente; e c) selecionar alunos para

Movimento, Porto Alegre, v. 15, n. 01, p. 241-258, janeiro/março de 2009. 
competições e apresentações tanto dentro da escola, quanto com outras escolas."

Na prática e de modo geral, a avaliação em Educação Física é realizada pela escola tradicional de três maneiras: através da valoração da presença em aula, sendo esta o único item avaliado; através da autoavaliação, realizada pelos alunos, e muitas vezes, sem a orientação do professor sobre critérios de avaliação, sobre a importância de esta corresponder à realidade, etc.; e através da avaliação das performances dos alunos, que valoriza a aptidão física e considera como itens avaliativos a técnica, o domínio das regras, o desenvolvimento das habilidades motoras, entre outros.

É, portanto, realizando avaliações que enfatizam as diferenças entre os alunos, que desvalorizam a Educação Física através da exigência mínima da presença em aula, e ao selecionar conteúdos que valorizam os mais aptos e que excluem socialmente os indivíduos, ao negar-lhes a possibilidade de apreender informações e conhecimentos sobre cidadania, história, a ordem social vigente no país, e sobre seus limites e potenciais, que a Educação Física, como elemento da escola tradicional, se organiza para que a função destinada a essa pelo capitalismo vigore plenamente.

\section{A EDUCAÇÃo FÍSICA E A AVALIAÇÃo SOB OS MOLDES DA ESCOLA CICLADA}

Na escola ciclada, a Educação Física tem se apresentado de forma diversificada, subjetiva e com problemas identificados no modelo da escola tradicional. Credita-se tal situação ao fato de que esta forma de ensino, por contrariar a lógica capitalista, que configura a escola seriada (tradicional), encontra barreiras para sua implantação e esbarra nas dificuldades pessoais e problemas de formação dos professores. Entretanto, ela também apresenta pontos comuns e evoluções importantes para a Educação Física escolar, sobre os quais discorreremos nesta parte do texto.

Com a participação do discente na construção do ensino, a escola ciclada destaca e valoriza os conhecimentos e a cultura deste,

Movimento, Porto Alegre, v. 15, n. 01, p. 241-258, janeiro/março de 2009. 
e proporciona-lhe a possibilidade de aprender e desenvolver praticamente: a autonomia, a responsabilidade social, a cidadania, a cooperação, etc., atuando assim para a formação completa do indivíduo. Contudo, para que isso ocorra é fundamental que as hierarquias de poder (citadas anteriormente) sejam de fato dissolvidas e que uma relação horizontal seja estabelecida entre professor e aluno, visto que são as relações de poder que geram, na escola, os "juízos de valor" que tanto influenciam as posturas de professores e de alunos, e a avaliação que o primeiro realiza.

Quanto à avaliação em Educação Física, em experiências descritas por Ferreira (2003) observou-se que, apesar de ser comum a utilização de elementos avaliativos como presença, pontualidade, participação, uniforme e etc., e constatar-se a realização de avaliações formais, tais como: testes escritos, apresentação de seminários, entre outros; a ênfase é dada à apreensão de novos conhecimentos, ou seja, o professor avalia os conhecimentos prévios (ao conteúdo) que o aluno apresenta e posteriormente avalia os conhecimentos que este adquiriu, enfatizando a qualidade do desenvolvimento e da aprendizagem ocorrida, sendo "[...] que a avaliação, num currículo por ciclos, se torna uma prática cotidiana, em que o/a docente busca conhecer seu aluno/a num processo contínuo, inacabado." (FERREIRA, 2003, p. 143).

Os resultados dessas avaliações são utilizados para a verificação da aprendizagem e possíveis dificuldades apresentadas pelo aluno, com o intuito de servirem como orientação dos futuros trabalhos, atividades, programas, etc.

A Educação Física, nesta escola, ganha novas perspectivas de realização dos seus conteúdos, com a possibilidade de interação entre os alunos e professores, que buscam diversificar a utilização dos espaços e das tecnologias, quebrando o paradigma da quadra como local de excelência da Educação Física, bem como a seleção de conteúdos que causam reflexão e que sejam diferentes do futebol, do vôlei e a inserção de aulas teóricas, de leitura e escrita.

E assim, partindo dessa estrutura, e apesar de reconhecer que esta apresenta tanto êxitos como fracassos, acreditamos que:

Movimento, Porto Alegre, v. 15, n. 01, p. 241-258, janeiro/março de 2009. 
[...] aqui se abre uma possibilidade fundamental para o ensino da EF: contribuir para que as novas gerações descubram, usufruam e reinventem a cultura corporal de movimento que lhes foi legada. E mais: que façam isto desmistificando seus significados sócio-históricos. [...] Em outras palavras, mais do que a transmissão de conteúdos didáticos, trata-se de fomentar uma educação crítica que promova a formação cultural e a educação política de nossos/ as alunos/as [....] ( FERREIRA, 2003, p. 67).

\section{CONSIDERAÇõES FINAIS}

No contexto social atual é importante destacar as necessidades de se buscar formas diferenciadas de ensino, que superem o modelo da escola tradicional - que, como destacamos, exerce papéis e funções problemáticas para a educação democrática que almejamos. Há a necessidade de se ampliar o espaço e o conhecimento da Educação Física escolar e de aprimorarem-se as atuações e formações do corpo docente da área. Em outras palavras, mais do que reconhecer os problemas que a escola apresenta, há a necessidade de se trabalhar em prol da construção de práticas e teorias que possibilitem mudanças na estrutura tradicional escolar.

É neste sentido que a escola ciclada adquire espaço, ao buscar romper com a estrutura tradicional escolar e implantar inovadoras e democráticas formas de construção do saber e dos elementos que a constituem. Atuando, apesar de apresentar tanto êxitos como fracassos, “[...] não uma mera solução pedagógica [...] e sim como um longo e necessário processo de resistência de professores, alunos e pais à lógica excludente e seletiva da escola" (FREITAS, 2003b, p. 36).

A respeito da avaliação em geral e da específica para área de Educação Física, a escola ciclada obteve conquistas importantes, que demonstram as reais possibilidades e relevância da atuação, de todas essas estruturas, para o desenvolvimento e formação dos discentes; tais como: a legitimização da Educação Física escolar, dos conteúdos sóciohistóricos como pertinentes à disciplina, da avaliação como elemento essencial ao desenvolvimento do conhecimento, da

Movimento, Porto Alegre, v. 15, n. 01, p. 241-258, janeiro/março de 2009. 
importância da avaliação em EF ser coerente e estar comprometida com a formação do discente.

Portanto, a escola ciclada representa e prova que é possível a criação e desenvolvimento de processos educacionais, diferentes das produzidas pela escola tradicional e pelo sistema capitalista, e que a realidade social, histórica e econômica em que vivemos é passível de mudança, visto que esta não representa a única e verdadeira realidade e que é mantida e reproduzida pela educação tradicional. Por compartilhar com essa forma de pensar a educação e reconhecer a avaliação como aspecto fundamental para qualquer forma de ensino, considera ser importante e indispensável a busca pelo aperfeiçoamento teórico desta e de sua atuação, para que as transformações objetivadas sejam efetivas.

The Physical Education School Evaluation: the
comparison between traditional school and
"ciclada" school
Abstract: In the present work, a comparative analysis
between the schools traditional and "cycling" was
become fulfilled, thinking about as if it would give to
the evaluation in the Physical Education from these
two perspectives. To develop the study it was essential
to analyze the pertaining to school structures: theoretical
base, methodology of education, politician-pedagogical
project; as well as, the social functions exerted by
these schools and the relations constructed for them
in the daily pertaining to school. As result of this study
was verified that the evaluation in Physical Education,
carried through for these schools, uses similar
evaluative instruments, such as: the presence in
lesson, the auto-evaluation and the performance of
the pupils, and also theoretical lessons and written
tests, however, the evaluation carried through for the
traditional school are guided for the election and
classification of the learning, differently of the "cycling"
school, whose evaluation is guided for the development
of the learning and the formation of active and socially
independent individuals, capable to reflect on proper
the practical one and the social reality which belong.
Keywords: Physical education. Evaluation. Curriculum.
Education, primary and secondary.

Movimento, Porto Alegre, v. 15, n. 01, p. 241-258, janeiro/março de 2009. 


La evaluación de la educación física en la escuela:
la comparación entre la escuela tradicional y la
escuela ciclada
Resúmen: En el trabajo, un análisis comparativo entre
las escuelas tradicionales y "ciclada" fue realizado, pen-
sando como si diera a la evaluación en la educación
física en las dos perspectivas. Para desarrollar el estudio
fue esencial analizar las estructuras de la escuela: la
base teórica, metodología de la educación, proyecto po-
lítico-pedagógico; así como, las funciones sociales
ejercidas por estas escuelas y las relaciones construidas
para ellas en el cotidiano de la escuela. El resultado de
este estudio fue verificado que la evaluación en la
educación física, llevada a través de estas escuelas,
utiliza los instrumentos evaluativos similares, por ejemplo:
la presencia en la lección, la automóvil-evaluación y el
funcionamiento de las pupilas, y también las lecciones
teóricas y las pruebas escritas, sin embargo, la
evaluación llevadas a través de la escuela tradicional se
dirige para la elección y la clasificación de aprender,
diferentemente de la escuela "ciclada", en que la
evaluación se dirige para el desarrollo de aprender y la
formación de individuos activos y socialmente
independientes, capacitados de reflejar la realidad social
que pertenezcan.
Palabras-Clave: Educación Física. Evaluación.
Curriculum. Educación primaria y secundaria.

\section{REFERÊNCIAS}

BETTI, M. Educação Física e Sociedade. São Paulo: Movimento, 1991.

DALBEN, A. I. L. F. Singular ou plural? Eis a escola em questão. Belo Horizonte: GAME, FAE-UFMG, 2000.

DAOLIO,J. Cultura: Educação Física e Futebol. 2. ed. rev. e ampl. Campinas, SP: Unicamp, 2003. (Coleção Livro-Texto).

FERREIRA, M. G. Limites e Possibilidades da Educação Física no Contexto da Escola Cidadã: Um estudo em escolas da rede municipal de Porto Alegre (RS). 212fls. Tese (Doutorado em Educação). Pontifícia Universidade Católica de São Paulo, São Paulo, 2003.

FREITAS, L. C. Ciclos, Seriação e Avaliação: confronto de lógicas. São Paulo: Moderna, 2003b. (Coleção cotidiano escolar).

Movimento, Porto Alegre, v. 15, n. 01, p. 241-258, janeiro/março de 2009. 
Questões de avaliação educacional. Campinas: Komedi, 2003a.

. A dialética da eliminação no processo seletivo. Educação e Sociedade, Campinas, n. 39, p. 265-285, 1999.

SOARES, C. L. Metodologia do Ensino de Educação Física. São Paulo: Cortez, 1992. (Coleção magistério. $2^{2}$ grau. Série formação do professor).

Movimento, Porto Alegre, v. 15, n. 01, p. 241-258, janeiro/março de 2009. 